\title{
Mobility of diesel versus non-diesel coal miners: some evidence on the healthy worker effect
}

\author{
RG AMES AND B TRENT \\ From the Appalachian Laboratories for Occupational Safety and Health, Morgantown, West Virginia 26505, \\ USA
}

ABSTRACT Workers who are particulary susceptible to the effects of their occupational exposure, from the perspective of the healthy worker effect, soon leave the workplace. The result of this mobility, called survival bias, is that cross sectional studies based on the survivors underestimate the true risk of occupational exposures. Two questions are addressed in this empirical study of the "survival bias" component of the "healthy worker" effect. Do miners with respiratory impairment or symptoms disproportionately leave jobs that have a potentially harmful respiratory exposure? And does the presence of an additional potentially harmful respiratory exposure, in this case diesel emissions, accelerate the rate of mobility for miners with respiratory impairment or symptoms? No confirmation was found for the survival effect in a study of 738 diesel and 420 non-diesel US underground coal miners. No additional increment in mobility was associated with exposure to both coal mine dust and diesel emissions.

The "healthy worker effect" is part of the folklore of occupational epidemiology and was documented nearly 100 years ago in the work of Ogle. ${ }^{1}$ Almost every study of the health effects of occupational exposure pays recognition to the healthy worker effect through the caveats that "of course, employed populations are healthier", and "of course, we are only studying the survivors". While the wording may vary, the message is clear: people in ill health or those overly susceptible to occupational exposure are disproportionately underrepresented in the workforce in any occupation. The result is that an unbiased assessment of the health outcomes resulting from occupational exposure is impossible. One simply has to assume that, for the mortality or morbidity under consideration, selection and survival effects are negligible. Both selection and survival, as parts of the healthy worker effect, are themselves part of the broader issue of sample selection bias. While the existence of a healthy worker effect is commonly reported to lead to an underestimate of the effects of occupational exposure, alternative views are possible. For very undesirable work, selectivity may retain only workers who could not move to a better job. The result would be an aggregation within the workplace of unhealthy rather than healthy workers.

Received 8 November 1982

Accepted 14 March 1983
Three related issues have evolved as areas of concern regarding the healthy worker effect.

\section{Selection effect}

Firstly, employed populations are, by the fact of employment, selected by health status and are thus more healthy than an average based on the total population. ${ }^{2-4}$ This "selection effect" biases mortality comparisons when occupational groups are compared with the total population, as is frequently done in the calculation of standardised mortality ratios (SMRs). The outcome of selection effect bias is reported to be lowered SMRs. ${ }^{256}$

Selection has been studied with conflicting results. Shindell et al think that the selection effect is an artifact of incomplete mortality ascertainment in SMR studies due to inadequate vital status search methods. ${ }^{7}$ McMichael, ${ }^{8}$ McMichael et al, ${ }^{9}$ and Fox Collier ${ }^{2}$ think that the selection effect is real, causespecific (also Enterline ${ }^{10}$ and Gaffrey ${ }^{11}$ ), and dissipates over time (also Seltzer and Jablon ${ }^{5}$ ).

\section{Survival effect}

Secondly, people particularly susceptible to the effects of specific occupational exposures would leave the workplace soon after initial employment. A "survival effect" bias is thus created because 
those employed in an industry, as seen at any cross sectional point, are the "survivors" of occupational exposures. ${ }^{2}$

The survival effect, while having high intuitive appeal, has had fewer empirical validations in field settings for various reasons. Frequent problems are lack of a prospective mode of data collection and inadequate baseline health characterisation.

\section{Other biasing effects}

Finally, other biasing effects that are considered within the healthy worker effect include "study loss over time" 12 and the "period of follow up." The latter may be important in some studies of cancer epidemiology due to a latency period. ${ }^{13}$ A qualifying period for cohort inclusion, say 10 years, may reduce this effect. ${ }^{14}$ The duration of follow up is important because the health advantage to the employed group resulting from preselection dissipates over time. ${ }^{5}$ This health advantage apparently biases risk estimates for respiratory disease and lung cancer more than for circulatory disease and "all cancers." 10

\section{A study of survival bias}

The present paper examines the survival effect based on the mobility of US underground coal miners who work in mines that use diesel engines underground compared with the mobility of miners who work in mines that do not use diesels underground.

There are two questions. Do miners with respiratory impairment or symptoms disproportionately leave jobs which have a potentially harmful respiratory effect? And, does this presence of an additional potentially harmful respiratory exposure, in this case diesel emissions, accelerate the rate of mobility for miners with respiratory impairment or symptoms?

Answers to these two questions bear directly on the general issue of the existence of the survival aspect of the healthy worker effect and the degree to which survival might be related to actual or perceived health hazards. The issues of how representative employed populations are of the US total population-that is, the selection effect-and the impact of duration of follow up on SMR values, or related issues, are not dealt with in this paper.

\section{Data and methods}

The present study is part of a programme of research into the health effects of the use of diesel engines in underground mines. A subsample of six coal mines using diesel engines underground in 1977 (comprising 738 miners) was drawn from mines in Kentucky, Colorado, Utah, and Wyoming. Diesel equipment in these mines was variously used in face hauling, in mucking operations, and for transporting personnel, equipment, and supplies. Each diesel mine was matched with a control mine near the diesel operation (420 miners). Thus we are making comparisons within an occupational group and thereby avoiding the selection effects typically encountered in using external comparison groups. ${ }^{1516}$

Both diesel and non-diesel miners were, in 1977, given a chest radiograph evaluated for coal workers' pneumoconiosis, spirometry to measure ventilatory function, and administered a questionnaire to determine respiratory symptoms, smoking history, and occupational history. In early 1982 the 1977 work rosters were updated by the mines to indicate employment status in January 1982 so that five year prospective mobility rates could be determined. A discussion of the respiratory impairment measures has been reported previously. ${ }^{17}$ These respiratory measures are pertinent to the concerns that researchers have regarding the acute effects of diesel emissions. Diesel emissions contain aerosol particulates that are cleared by the respiratory system as well as gases with potential respiratory system effects, notably carbon monoxide (CO), oxides of nitrogen $\left(\mathrm{NO}_{\mathbf{x}}\right)$, sulphur dioxide $\left(\mathrm{SO}_{2}\right)$, and aldehydes. ${ }^{17}$ Airways obstruction is measured by the ratio of forced expiratory volume in one second $\left(F E V_{1}\right)$ to the forced vital capacity (FVC).$^{18}$ Airways restriction is measured by the percentage prediction of FVC based on age, sex, race, height, and weight norms. ${ }^{18}$ We used norms described by Knudson et al. ${ }^{19}$ Measures of small airways function are based on maximum expiratory flow rate (Parkes ${ }^{18}$ pp 6-8). We used flow rate at $50 \%$ of FVC. Because no evidence points to a linkage between mild reductions in lung function, as indexed by spirometry measures, and perception of reduced lung function, ${ }^{20}$ respiratory symptoms, based on questions using a modified Medical Research Council (MRC) questionnaire, were also included. The symptoms are: persistent cough, defined as cough on most days for as much as three months each year; persistent phlegm, defined as bringing up phlegm most days for as much as three months each year; and breathlessness, defined as having to stop for breath when walking at one's own pace on level ground. The prevalence of coal workers' pneumoconiosis in this sample was so low that it was not further analysed.

Social and background characteristics of the miners possibly related to health or mobility were examined before the measures of respiratory 
impairment and symptoms. Since age was found to be a strong overall predictor of mobility, mobility rates were age adjusted to the "all mines" total.

The population of this study was restricted to miners under age 50 to avoid a retirement bias.

Chi-squared was used to test relationships between various independent variables and five year mobility within mine type, between mine type, and for the total study group.

\section{Social and demographic correlates of mobility}

The overall mobility, expressed as percentage leaving in five years, was identical for both mine types, $26 \%$ in diesel and non-diesel mines, and hence not statistically significant (table 1 ). When mobility was analysed by miners' characteristics, some differences occurred.

As expected, women overall had a statistically significantly higher five year mobility rate than men, $62 \%$ compared with $25 \%$. Within both diesel and non-diesel mines women were significantly more likely to leave than men.

Overall, whites had a significantly higher rate of mobility than non-whites, $27 \%$ compared with $15 \%$. Within non-diesel mines whites were significantly more likely to leave than non-whites.

As expected, never married and not currently married miners had a significantly higher mobility rate than currently married miners, $32 \%$ and $40 \%$ compared with $25 \%$ in the total sample.

The younger the miner the higher the mobility

Table 1 Percentage leaving employment at mine between 1977 and 1982 by background characteristics and mine type. (Miners under 50: age adjusted) (Percentage bases in parentheses)

\begin{tabular}{|c|c|c|c|}
\hline \multirow[t]{2}{*}{ Background characteristic } & \multirow{2}{*}{$\begin{array}{l}\% \text { Leaving } \\
\text { All mines }\end{array}$} & \multicolumn{2}{|c|}{ \% Leaving by mine type } \\
\hline & & Diesel mines & Non-diesel mines \\
\hline All miners & $26 \%(1158)$ & $26 \%(738)$ & $26 \%(420) \mathrm{NS}$ \\
\hline $\begin{array}{l}\text { Sex: } \\
\text { Men } \\
\text { Women }\end{array}$ & $\begin{array}{l}25 \%(1121) \\
62 \%(37)\end{array}$ & $\begin{array}{l}25 \%(708) \\
57 \%(30) \\
*\end{array}$ & $\begin{array}{l}25 \%(413) \mathrm{NS} \\
86 \%(7) \mathrm{NS} \\
*\end{array}$ \\
\hline $\begin{array}{l}\text { Race: } \\
\text { White } \\
\text { Non-white }\end{array}$ & $\begin{array}{l}27 \%(1085) \\
15 \%(73)\end{array}$ & $\begin{array}{l}26 \%(732) \\
17 \%(6) \\
\text { NS }\end{array}$ & $\begin{array}{l}29 \%(353) \mathrm{NS} \\
15 \%(67) \mathrm{NS}\end{array}$ \\
\hline $\begin{array}{l}\text { Marital status: } \\
\text { Never married } \\
\text { Not currently married } \\
\text { Currently married }\end{array}$ & $\begin{array}{l}32 \%(125) \\
40 \%(62) \\
25 \%(971)\end{array}$ & $\begin{array}{l}33 \%(72) \\
38 \%(34) \\
25 \%(632) \\
\text { NS }\end{array}$ & $\begin{array}{l}30 \%(53) \text { NS } \\
43 \%(28) \text { NS } \\
24 \%(339) \text { NS } \\
\text { NS }\end{array}$ \\
\hline $\begin{array}{l}\text { Age (unadjusted): } \\
18-25 \\
26-40 \\
41-50\end{array}$ & $\begin{array}{l}31 \%(344) \\
25 \%(648) \\
20 \%(166)\end{array}$ & $\begin{array}{l}30 \%(241) \\
25 \%(413) \\
25 \%(84) \\
\text { NS }\end{array}$ & $\begin{array}{l}32 \%(103) \text { NS } \\
25 \%(235) \text { NS } \\
15 \%(82) \mathrm{NS}\end{array}$ \\
\hline $\begin{array}{l}\text { Current smoking habits: } \\
\text { Current smoker, } 1977 \\
\text { Non- or ex-smoker, } 1977\end{array}$ & $\begin{array}{l}25 \%(560) \\
28 \%(598) \\
\text { NS }\end{array}$ & $\begin{array}{l}24 \%(362) \\
29 \%(376) \\
\text { NS }\end{array}$ & $\begin{array}{l}26 \%(198) \text { NS } \\
26 \%(222) \text { NS } \\
\text { NS }\end{array}$ \\
\hline $\begin{array}{l}\text { Education (years): } \\
<12 \\
12 \\
>12\end{array}$ & $\begin{array}{l}19 \%(251) \\
26 \%(589) \\
35 \%(318) \\
*\end{array}$ & $\begin{array}{l}19 \%(172) \\
26 \%(356) \\
36 \%(210) \\
*\end{array}$ & $\begin{array}{l}20 \%(79) \text { NS } \\
26 \%(233) \text { NS } \\
32 \%(108) \text { NS } \\
\text { NS }\end{array}$ \\
\hline $\begin{array}{l}\text { Years mining: } \\
<4 \\
4-7 \\
>7\end{array}$ & $\begin{array}{l}32 \%(639) \\
20 \%(325) \\
10 \%(194) \\
{ }^{*}\end{array}$ & $\begin{array}{l}30 \%(499) \\
18 \%(190) \\
12 \%(49)\end{array}$ & $\begin{array}{l}39 \%(140) \text { NS } \\
24 \%(135) \text { NS } \\
9 \%(145) \text { NS } \\
{ }^{*}\end{array}$ \\
\hline $\begin{array}{l}\text { Years underground: } \\
<4 \\
4-7 \\
>7\end{array}$ & $\begin{array}{l}29 \%(836) \\
21 \%(186) \\
8 \%(136)\end{array}$ & $\begin{array}{l}28 \%(674) \\
9 \%(43) \\
14 \%(21)\end{array}$ & $\begin{array}{l}35 \%(162) \text { NS } \\
24 \%(143) * * \\
7 \%(115) \mathrm{NS}\end{array}$ \\
\hline
\end{tabular}

${ }^{*}$ Indicates significant difference within mine type at alpha 0.05 .

**Indicates significant difference between mine type at alpha 0.05.

NS $=$ Not significant. 
rate. Overall rates ranged from a low of $20 \%$ for miners over age 40 to a high of $31 \%$ for miners aged 18-25. These differences were significant. Age differences in mobility were significant in the nondiesel sample but not in the diesel sample.

Mobility rates were almost identical between miners who were current smokers in 1977 and those who were not, $25 \%$ compared with $28 \%$. There was a slight tendency among diesel miners for ex- and non-smoking miners to have a higher rate of mobility compared with smoking miners, $29 \%$ compared with $24 \%$. No differences in mobility rates, either total or within mine type, attained statistical significance.

Mobility was positively and significantly related to education overall and in the diesel miners. The rates range in the total from $19 \%$ for those with less than high school graduation to $35 \%$ for those with at least some college education.

The less the total mining experience, both underground and above ground, the greater the mobility. For those with less than four years of mining, the mobility rate was $32 \%$, and for those with more than seven years of mining, the mobility rate was $10 \%$. This trend was more extreme in the non-diesel miners than in the diesel miners. Mobility differences by total years mining, total and within mine type, are statistically significant.

Finally, the less the underground mining experience, the higher the mobility. For those with less than four years underground, the mobility rate was $29 \%$ compared with $8 \%$ for those with more than seven years of underground mining. Mobility differ- ences by years underground were statistically significant within both diesel and non-diesel mines.

Only one diesel, non-diesel mobility rate comparison was significant for any of the social and demographic characteristics. That difference was for four to seven years underground, and was in the opposite direction than hypothesised.

\section{Health correlates of mobility}

Miners having severe airways obstruction left their place of employment at virtually the same rate as miners having moderate or no obstruction, $25 \%$ compared with $26 \%$, not statistically significant (table 2).

Miners with moderate pulmonary restriction had similar rates of mobility as miners with either severe or mild restriction, $30 \%$ compared with $22 \%$ and $26 \%$; the differences are not significant. Whereas diesel miners with middle range values for restrictive disease had the highest rates of mobility, no mobility rate differences by restrictive disease were statistically significant.

Miners with middle range values of expiratory flow rates at $50 \%$ of FVC had significantly higher rates of mobility than those with low or high flow rates, $29 \%$ compared with $26 \%$ and $22 \%$ in the total sample. The within diesel differences achieved significance although the within non-diesel did not.

Miners with persistent productive cough, persistent phlegm, and shortness of breath were no more likely to be mobile than miners without these respiratory symptoms (table 3 ). Respiratory symp-

Table 2 Percentage leaving employment at mine between 1977 and 1982 by respiratory measures and mine type. (Miners under 50: age adjusted) (Percentage bases in parentheses)

\begin{tabular}{|c|c|c|c|}
\hline \multirow{2}{*}{$\begin{array}{l}\text { Respiratory } \\
\text { Measures }\end{array}$} & \multirow{2}{*}{$\begin{array}{l}\text { \% Leaving } \\
\text { All mines }\end{array}$} & \multicolumn{2}{|c|}{ \% Leaving by mine type } \\
\hline & & Diesel mines & Non-diesel mines \\
\hline \multicolumn{4}{|c|}{$\begin{array}{l}\text { Airways obstruction } \\
\text { (FEV/FVC \%): }\end{array}$} \\
\hline $\begin{array}{l}<66 \\
66-75 \\
>75\end{array}$ & $\begin{array}{l}25 \%(98) \\
27 \%(260) \\
26 \%(800) \\
\text { NS }\end{array}$ & $\begin{array}{l}24 \%(78) \\
26 \%(141) \\
27 \%(519) \\
\text { NS }\end{array}$ & $\begin{array}{l}30 \%(20) \text { NS } \\
29 \%(119) \text { NS } \\
25 \%(281) \text { NS } \\
\text { NS }\end{array}$ \\
\hline \multicolumn{4}{|c|}{$\begin{array}{l}\text { Airways restriction } \\
\text { (FVC } \mathrm{v} \text { standard, } \% \text { of prediction): }\end{array}$} \\
\hline $\begin{array}{l}<66 \\
66-75 \\
>75\end{array}$ & $\begin{array}{l}22 \%(61) \\
30 \%(27) \\
26 \%(1070) \\
\text { NS }\end{array}$ & $\begin{array}{l}22 \%(55) \\
35 \%(23) \\
26 \%(660) \\
\text { NS }\end{array}$ & $\begin{array}{l}17 \%(6) \text { NS } \\
0 \%(4) \text { NS } \\
26 \%(410) \text { NS } \\
\text { NS }\end{array}$ \\
\hline \multicolumn{4}{|c|}{$\begin{array}{l}\text { Small airways function } \\
\text { (Max exp flow rate at } 50 \% \text { of FVC): }\end{array}$} \\
\hline $\begin{array}{l}<3.01 \mathrm{l} / \mathrm{s} \\
3.01-5.00 \mathrm{l} / \mathrm{s} \\
>5.00 \mathrm{~V} / \mathrm{s}\end{array}$ & $\begin{array}{l}26 \%(211) \\
29 \%(569) \\
22 \%(378)\end{array}$ & $\begin{array}{l}24 \%(132) \\
31 \%(337) \\
21 \%(269)\end{array}$ & $\begin{array}{l}29 \%(79) \text { NS } \\
26 \%(232) \text { NS } \\
25 \%(109) \text { NS } \\
\text { NS }\end{array}$ \\
\hline
\end{tabular}

*Indicates significant difference within mine type at alpha 0.05 .

NS $=$ Not significant. 
Table 3 Percentage leaving employment at mine between 1977 and 1982 by respiratory symptoms and mine type. (Miners under 50 years: age-adjusted) (Percentage bases in parentheses)

\begin{tabular}{|c|c|c|c|}
\hline \multirow{2}{*}{$\begin{array}{l}\text { Respiratory } \\
\text { symptoms }\end{array}$} & \multirow{2}{*}{$\begin{array}{l}\% \text { Leaving } \\
\text { All mines }\end{array}$} & \multicolumn{2}{|c|}{$\%$ Leaving by mine type } \\
\hline & & Diesel mines & Non-diesel mines \\
\hline $\begin{array}{l}\text { Persistent co } \\
\text { Yes } \\
\text { No }\end{array}$ & $\begin{array}{l}24 \%(233) \\
26 \%(925) \\
\text { NS }\end{array}$ & $\begin{array}{l}27 \%(166) \\
26 \%(572) \\
\text { NS }\end{array}$ & $\begin{array}{l}18 \%(67) \mathrm{NS} \\
27 \%(353) \mathrm{NS} \\
\mathrm{NS}\end{array}$ \\
\hline $\begin{array}{l}\text { Persistent ph } \\
\text { Yes } \\
\text { No }\end{array}$ & $\begin{array}{l}25 \%(266) \\
27 \%(892) \\
\text { NS }\end{array}$ & $\begin{array}{l}25 \%(177) \\
27 \%(561) \\
\text { NS }\end{array}$ & $\begin{array}{l}24 \%(89) \mathrm{NS} \\
27 \%(331) \mathrm{NS} \\
\mathrm{NS}\end{array}$ \\
\hline $\begin{array}{l}\text { Breathlessne } \\
\text { Yes } \\
\text { No }\end{array}$ & $\begin{array}{l}15 \%(91) \\
27 \%(1067)\end{array}$ & $\begin{array}{l}17 \%(60) \\
27 \%(678) \\
\text { NS }\end{array}$ & 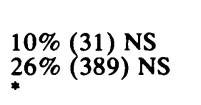 \\
\hline
\end{tabular}

*Indicates significant difference within mine type at alpha 0.05 .

toms were not significantly related to mobility in the predicted direction within mine type, nor were there significant differences between mine types within respiratory symptom categories.

\section{Discussion}

The survival bias component of the healthy worker effect predicts that impaired workers or workers with heightened susceptibility or sensitivity to specific occupational exposures leave the workforce setting at a higher rate than others. The net result is that sccupational epidemiology studies underestimate the effects of occupational exposures by studying only the survivors of the workplace.

The present study attempts an empirical assessment of the survival effect by using a sample of coal mines using diesel equipment underground, a matched comparison sample of neighbouring nondiesel mines, and predicting subsequent mobility based on the health status and social characteristics of the miners in 1977.

Our assumptions in this study are that coal mine dust represents a threat to miners' respiratory health, and that the addition of underground diesel emissions represents a potential additional threat. Under these assumptions, we predict that miners experiencing respiratory symptoms or impairment in 1977 will subsequently leave the workforce at a higher rate than those who do not. Further, we predict that this trend should be enhanced for those exposed to two potential respiratory hazards (coal mine dust plus diesel emissions) compared with those exposed only to one potential hazard (coal mine dust alone.).

Our data showed mobility to be related to many of the variables social scientists would expect on the basis of migration theory and other social models ${ }^{21}$ - that is, higher for women (in a male dominated workforce), higher for the non-married than the currently married, higher for the young than the old, higher for those with more education, and higher for those with short tenure in the industry. Given the existence of the social correlates in the predicted direction, one can place more faith in the lack of association in the hypothesised direction that we found between respiratory measures and symptoms and subsequent mobility.

Our data did not support the predictions based on the survival component of the healthy worker effect. Rates of mobility for persons with airways obstruction and airways restriction were not significantly higher than for those with normal respiratory function. There was some evidence that diesel miners with moderate small airways disease, as indexed by middle range values on maximum expiratory flow rate at $50 \%$ of FVC, had higher mobility than miners with no evidence of small airways disease.

Miners with respiratory symptoms had no higher mobility rates than those without.

In summary, we found no evidence of a survival effect in this sample of diesel and non-diesel coal miners. These results are in essential disagreement with the findings of Fox and Collier ${ }^{2}$ and Vinni and Hakama, ${ }^{6}$ but in agreement with those of Cochrane et $a^{22}$ in their study of mortality among coal miners in the Rhondda Fach. We found mobility to characterise younger workers and those with short tenure underground and in the mining industry-that is, precisely those who would be least likely to show respiratory symptoms or disease. Against the backdrop of these social factors, the presence of respiratory disease and symptoms played no obvious part in occupational mobility. No additional increment in mobility was associated with exposure to both coal mine dust and diesel emissions. 


\section{References}

${ }^{1}$ Ogle W. Letter to the Registrar-General on the mortality in the registration districts of England and Wales during the ten years 1871-80. Supplement to the 45th Annual Report of the Registrar-General of Births, Deaths, and Marriages, in England, 1885. p xxiii.

${ }^{2}$ Fox AJ, Collier PF. Low mortality rates in industrial cohort studies due to selection for work and survival in the industry. British Journal of Preventive and Social Medicine 1976;30:225-30.

${ }^{3}$ Goldsmith JR. What do we expect from an occupational cohort? [Letter]. JOM 1976;17:126-7.

${ }^{4}$ Kitigawa EM, Hauser PM. Differential mortality in the United States. Boston: Harvard University Press, 1973.

${ }^{5}$ Seltzer CC, Jablon S. Effects of selection on mortality. Am J Epidemiol 1974;100:367-72.

- Vinni K, Hakama M. Healthy worker effect in the total Finnish population. Br J Ind Med 1980;37:180-4.

${ }^{7}$ Shindell S, Weisberg RF, Giefer EE. The "healthy worker effect"-fact or artifact?" JOM 1978;20:807-11.

${ }^{8}$ McMichael AJ. Standardized mortality ratios and the "healthy worker effect": scratching beneath the surface. JOM 1976;18: $165-8$.

${ }^{9}$ McMichael AJ, Haynes SG, Tyroler HA. Observations on the evaluation of occupational mortality data [Letter]. JOM 1976;17:128-31.

${ }^{10}$ Enterline PE. Not uniformly true for each cause of death [Letter]. JOM 1976;17:127-8.

"Gaffrey WR. Cause-specific mortality [Letter]. JOM
1976;17:127-8.

${ }^{12}$ Greenland S. Response and follow-up bias in cohort studies. Am $J$ Epidemiol 1977;106:184-7.

${ }^{13}$ Enterline PE. Estimating health risks in studies of the health effects of asbestos. Am Rev Respir Dis 1976;113:175-80.

14 Parkes HG, Veys CA, Waterhouse JAH, Peters A. Cancer mortality in the British rubber industry. $\mathrm{Br} J$ Ind Med 1982;39:209-20.

15 Enterline PE. Pitfalls in epidemiological research. JOM 1976;18:150-6.

${ }^{16}$ Redmond CK, Breslin PP. Comparison of methods for assessing occupational hazards. JOM 1975;17:313-7.

${ }^{17}$ Ames RG, Attfield MD, Hankinson J, Hearl FJ, Reger RB. Acute respiratory effects of exposure to diesel emissions in coal miners. Am Rev Respir Dis 1982;125:39-42.

18 Parkes WR. Occupational lung disorders. 2nd ed. London: Butterworths, 1982.

${ }^{19}$ Knudson RJ, Slatin RC, Lebowitz MD, Burrows B. The maximal expiratory flow-volume curve. Am Rev Respir Dis 1976;113:587-600.

${ }^{20}$ Gottfried SD, Altos MD, Kelsen SG, Cherniack NS. Perception of changes in airflow resistance in obstructive pulmonary disorders. Am Rev Respir Dis 1981;124:566-70.

${ }^{21}$ Richey NP. Explanations of migration. In: Inkeles A, ed. Annual reviews of sociology. Vol 2. Palo Alto, CA: Annual Reviews Inc, 1976:363-404.

${ }^{22}$ Cochrane AL, Moore F, Moncrief CB. Are coalminers with low risk factors for ischaemic heart disease at greater risk of developing progressive massive fibrosis? $\mathrm{Br} \mathrm{J}$ Ind Med 1982;39:265-8. 